\title{
Preliminary Study of a New Topology Permanent Magnet Flux Switching Motor for Electric Buses
}

\author{
Mohd Fairoz Omar*1, E. Sulaiman', M. Z. Ahmad ${ }^{3}$, J. A. Rani ${ }^{4}$, Aravind CV \\ 1,2,3,4 Faculty of Electrical and Electronics Engineering, Universiti Tun Hussein Onn Malaysia, Johor, Malaysia \\ ${ }^{5}$ School of Engineering, Taylor's University, Selangor Malaysia
}

\section{Article Info \\ Article history: \\ Received Nov 17, 2017 \\ Revised Jan 202018 \\ Accepted Mar 12, 2018}

\section{Keywords:}

Electric buses

Flux switching motor

Non-overlapped windings

Permanent magnet

Salient rotor

Three phase

\begin{abstract}
Electric buses (EBs) as public transit that have been introduced in modern countries recently are an alternative effort to reduce climate change and environmental impacts of fossil fuels. One example of the successfully developed motor for EBs is interior permanent magnet synchronous motor (IPMSM) with merits of heat dissipating, high torque per frame size and reliability influence by absence of brushes. However, the three-phase armature windings are wounded in the form of distributed windings, results in much copper loss, high coil end length and reduced the efficiency. The embedded rectangular magnets inside the rotor make rotor less robust, increased rotor weight and reduced the torque and power density. The present IPMSM has a complex structure which is relatively difficult to manufacture and tough in optimization process. The $7.0 \mathrm{~kg}$ volume of PM used in IPMSM is very high, which increases the cost of the machine. Therefore, a new topology of permanent magnet flux switching motor using wedge-shaped PM and single stator structure with the advantages of simple stator design, robust rotor structure, high of torque and power, and high efficiency is proposed. The design, flux linkage, back-emf, cogging torque, average torque, speed, and power of this new topology are investigated by JMAG-Designer version 14.1 via a 2D-FEA. The initial design of proposed motor produces torque and power of $905.9 \mathrm{Nm}$ and $57.75 \mathrm{~kW}$, respectively
\end{abstract}

Copyright $\odot 2018$ Institute of Advanced Engineering and Science. All rights reserved.

\section{Corresponding Author:}

Mohd Fairoz Omar,

Faculty of Electrical and Electronic Engineering,

Universiti Tun Hussein Onn Malaysia,

86400 Parit Raja, Johor, Malaysia.

Email: fairoz.omar@yahoo.com

\section{INTRODUCTION}

It has been extensively recognised that climate change and carbon emission are by far the biggest ordeals of the new millennium. The amplification in the number of automobiles is one of the key reasons and it was reported that there are currently almost 1 billion vehicles globally, consuming about 60 million barrels of oil per day (about $70 \%$ of the total oil production). On average, private vehicles consumed petroleum at about 36 million barrels/day and so emitted roughly 14 million tonnes of carbon dioxide daily. In addition, these same vehicles emitted 114 trillion British Thermal Units (BTU) of heat every day [1]. For Malaysian scenario, analysis on the consumption by fuel type showed that the share of petroleum products increased marginally from $57.0 \%$ in 2013 to $57.1 \%$ in 2014 . As such, petrol and diesel were the major contributors at $43.0 \%$ and $34.4 \%$, respectively. Moreover, data collected from 2005 to 2013 shows the number of registered vehicles has increased every year with an average increment rate of $6.8 \%$. In terms of $\mathrm{CO} 2$ emissions, the transportation sector continued to be one of the largest emitters in the country [2].

Governments worldwide are imposing strategies and plans to reduce carbon emission. By the year 2020, the United Kingdom is targeting to reduce carbon emissions by 45\% [3], [4]. European Union (EU) 
countries are planning to reduce their emissions of $20 \%$ by the year 2020 [5]. As for Malaysia, the government is committed to trim down carbon emission by $40 \%$ by the year 2020 and in line Malaysia Government Transformation Programme (GTP) 2.0, the government is dedicated to implementing Bus Rapid Transit (BRT) [6]. Green technology application in automotive has been identified as a viable solution to impede these vulnerabilities and promote a sustainable economy. Presently, one of the most prominent sustainable answers to strongly reduce oil consumption and carbon emissions lie in electric vehicles (EVs) and hybrid electric vehicles (HEVs). Based on the state of art, the technology of HEV considered better than $\mathrm{EV}$ and internal combustion engine vehicle (ICEV) due to the fact that the engine of the HEV can always operate in its most efficient mode, yielding super-ultra-low-emissions, and low fuel consumption than the ICEV while having the same range. Consequently, it has encouraged almost all car industrialists to improve and develop their own HEV models and commercialization of super-ultra-low-emission vehicles [7].

Recently, there are several types of electric machines used in HEVs such as dc motors, induction motors (IMs), switched reluctance motors (SRMs), permanent magnet synchronous motors (PMSMs) and flux switching motors (FSMs) [8], [9]. However, based on literatures regarding electric motors used in HEVs, only numerous type of electric motor have been studied for electric buses (EBs) which is outer rotor SRM (OR-SRM) and interior permanent magnet synchronous motor (IPMSM) as illustrated in Figure 1 [10], [11]. In [10], the 16S-18P OR-SRM design that offers a short flux path, low iron loss and capable to produce torque and power of $200 \mathrm{Nm}$ and $40 \mathrm{~kW}$, respectively. Besides, SRM absent of permanent magnet, inherent fault tolerance capabilities, simple and robust construction make SRM become more attractive for electric vehicle applications [12]. However, the SRM has the disadvantages of high torque ripple, high noise, vibrations and week magnetic communications between the coils due to unevenness of air gap [13]. Other drawbacks of OR-SRM include the use of position sensor which complicates the structure and makes the system less reliable for EBs [14], [15].

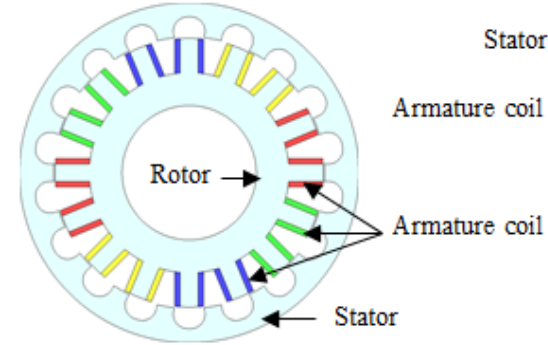

(a)

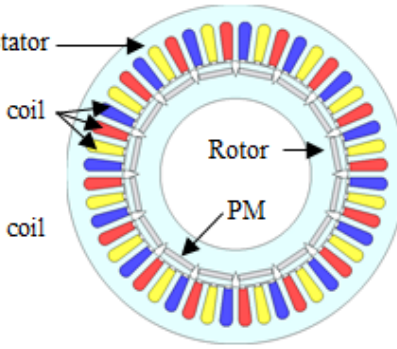

(b)

Figure 1. Example of Electric Motor used in EB, (a) 16S-18P OR-SRM and (b) 48S-8P IPMSM

On the other hand, author in [11] has introduced three-phase configuration of 48S-8P IPMSM with advantages of high torque and power densities, high torque capability at low speeds, wide operating speed range, high efficiencies over the speed range, high reliability, and acceptable cost. Moreover, 48S-8P IPMSM with embedded rectangular magnets are preferred since they generate less losses than rotor surface magnets, their risk of demagnetization during a stator short-circuit failure is lower, reliably fixed and bonded in the rotor. The motor have stator outer diameter, rotor outer diameter, air gap, and stack length of the motor are $396 \mathrm{~mm}, 260 \mathrm{~mm}, 1.5 \mathrm{~mm}$, and $225 \mathrm{~mm}$, respectively. Meanwhile, in electrical part, the supply voltage, current and armature current density are $440 \mathrm{~V}, 337.6 \mathrm{~A}$ and $35 \mathrm{Arms} / \mathrm{mm} 2$, respectively. Recent studies on the 48S-8P IPMSM shows at base speed of $2240 \mathrm{rpm}$, maximum capability of torque and power achieved are $639 \mathrm{Nm}$ and $150 \mathrm{~kW}$, respectively.

In spite of their good performances in term of torque and power, 48S-8P IPMSM stator and rotor structures as well as winding configurations can further be changed and improved. The three-phase armature windings are wounded in the form of distributed windings which results in much copper loss, high coil end length and thus, reducing the efficiency. IPMSM with embedded rectangular magnets inside the rotor make the motor less robust, increases the rotor weight and reduces the torque and power density. The present IPMSM has a complex structure which is relatively difficult to manufacture and tough in optimization process. The $7.0 \mathrm{~kg}$ volume of PM used in IPMSM is very high, which increases the cost of the machine.

In order to overcome the drawbacks of IPMSM, permanent magnet flux switching motor (PMFSM) is introduced with advantages of all active part placed on the stator which inherently reduces the copper loss, motor weight as well as increases the motor efficiency. Research on the PMFSM to date has been mainly not only focused on the general electromagnetic analysis, optimization of the inner rotor type [16], but also the

Preliminary Study of a New Topology Permanent Magnet Flux Switching Motor for... (Mohd Fairoz Omar) 
outer rotor PMFSM [17]. There are two types of stator, segmented and a single as well matched in designs using the rectangular-shaped, V-shaped and wedge-shaped PM. First outer rotor PMFSM introduced is on 2009 [18] with a novel 12 slots, 22 poles (12S-22P) with conventional rectangular-shaped of PM (I-PMFSM) for electric propulsion in a lightweight electric vehicle is presented. The design specifications, optimization, and performances can be obtained in [19] with advantages of high efficiency and high flux-weakening capability over the operational speed range. However, this design have some problems such as low rated speed and usage high current in order to produces a high torque and power. In addition, the segmented stator design make the motor structure become complex and difficult to manufacture.

Another example of outer rotor PMFSM is outer rotor PMFSM with wedge-shaped magnet (WPMFSM). The specifications, optimisation performances and comparison between outer rotor W-PMFSM, outer rotor I-PMFSM and a surface-mounted PMSM were explained in [20]. The outer rotor W-PMFSM has $12 \mathrm{~S}-22 \mathrm{P}$ configuration, while parameter of rotor outer diameter, rotor inner diameter and air-gap length are comparable with the outer rotor I-PMFSM in [19]. Figure 2 (a) show the structure of W-PMFSM. The WPMFSM has advantages of torque capability, high efficiency due to the less torque ripple and high PM flux linkage. Furthermore, W-PMFSM has a good flux weakening capability which is important to determine speed range and loading capability in high-speed mode. However, the peak-to peak value of cogging torque of outer rotor W-PMFSM is high compared to the surface-mounted SPMSM because of most of wedgeshaped PM part is placed in the stator led more flux linkage.

Figure 2 (b) shows the urban structure of inner rotor PMFSM with overlapped windings (OWPMFSM). The inner rotor OW-PMFSM has 24 slots and 16 poles, while the outer stator diameter, outer rotor diameter and stack length are set to $128 \mathrm{~mm}, 82.5 \mathrm{~mm}$ and $75 \mathrm{~mm}$, respectively [21]. In [21], the author claimed that the inner rotor OW-PMFSM produced flux linkage and back-emf of $115.28 \%$ higher than inner rotor non-overlapped windings (NOW-PMFSM) due to armature slot area was doubled. The torque density of OW-PMFSM is $65.2 \%$ higher than NOW-PMFSM, and $17.6 \%$ higher than the conventional 12S-10P NOW-PMFSM. In addition, the design of inner rotor give the advantage during operation at high speed. However, the OW-PMFSM suffers from high torque ripple due to high cogging torque and back-emf harmonics. In addition, the conventional rectangular-shaped PMs used on segmental stator make the structure more complex, hard to manufacture, not robust and tough to optimise.

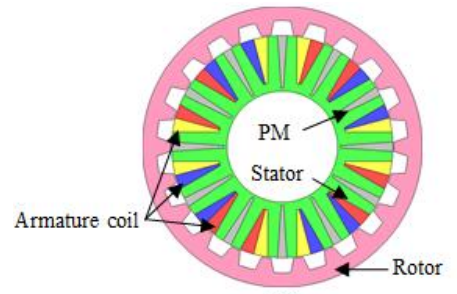

(a)

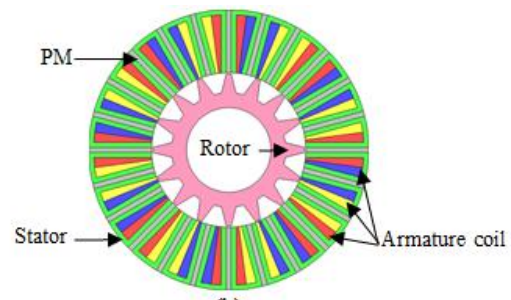

(b)

Figure 2. (a) 12S-22P PMFSM Outer Rotor with Wedge-Shaped PM and (b) 24S-16P PMFSM Inner Rotor with Rectangular-Shaped PM

Therefore, a new topology of three-phase inner rotor PMFSM using wedge-shaped PM and nonoverlapped armature windings placed on the stator is proposed. Both stator and rotor are designs with salient teeth and single structure that give advantages of easy to optimise and manufacture process. For the initial design, parameters for outer diameter, air gap length and stack length are based on existing IPMSM in [11] as per minimum requirement of EBs.

\section{RESEARCH METHODOLOGY}

Generally, the project implementation is divided into two phases, which are topology selection of inner rotor PMFSM and design various rotor pole of inner rotor PMFSM with wedge-shaped PM. Analytical study is completed by a 2D finite element analysis (2D-FEA) to obtain information that is not available through an actual device test and gave substantially greater insight into the device's performance. The 2DFEA software used is JMAG-designer version 14.1.

At the first phase, there are four topologies of inner rotor PMFSM to be analysed namely Model 1, Model 2, Model 3 and Model 4. Each model uses a combination of 24S-16P with non-overlapped windings and different structures of PM, stator and rotor. For Model 1 and Model 2, both design use segmental stator and salient teeth structure, but the PM shape of Model 1 and Model 2 is different in which rectangular-shaped 
and wedge-shaped, respectively. Meanwhile, Model 3 uses single stator and rotor structure as well as wedgeshaped of PM. For the Model 4, it use single stator structure, segmental rotor structure and wedge-shaped of PM. The structure characteristics of all models are summarized in Table 1.

Table 1. Structure Characteristics of Various Inner Rotor PMFSMs

\begin{tabular}{ccccc}
\hline Structur /Model & Model 1 & Model 2 & Model 3 & Model 4 \\
\hline Stator & Segmental & Segmental & Single & Single \\
Rotor & Single & Single & Single & Segmental \\
PM shape & Rectangular & Wedge & Wedge & Rectangular \\
\hline
\end{tabular}

To fairly compare with the existing 48S-8P IPMSM, stator outer diameter, air gap, stack length and PM weight are kept same for the proposed one. For electrical part, maximum voltage, maximum rated current, Ia, maximum current density, JA, and PM weight are set to $415 \mathrm{~V}, 240 \mathrm{Arms}, 35 \mathrm{Arms} / \mathrm{mm} 2$ and 7 $\mathrm{kg}$, respectively for all designs. The number of turns, $\mathrm{Na}$ and rated current, Irms is calculated based on Equation 1 and 2, respectively. Rotor tooth width, Rw and stator tooth width, Sw, stator back length, Sbl and $\mathrm{PM}$ width, PMw are determined by using Equation 3.

$$
\begin{aligned}
& N_{A}=\frac{J_{A} \alpha S_{A}}{I_{A}} \\
& I_{A}=\frac{J_{A} \alpha S_{A} \sqrt{2}}{N_{A}}
\end{aligned}
$$

where $J_{A}$ is the current density, $\alpha$ is filling factor, $S_{A}$ is the total area of the slot, and $I_{A}$ is current.

$$
R_{w}=S_{w}=P M_{w}=\frac{3 \pi S_{i d}}{4 N_{s}}=\frac{3 \pi S_{o d} K_{i o s}}{4 N_{s}}
$$

At the second phase, the design various rotor pole is studied purposely to determine the best rotor number to match with stator structure that selected in the previous phase. All designs will use the same stator structure and only rotor number will change. The possible combination stator slot and rotor pole are calculated based on Equation 4. Where $N_{s}, N_{r}, Q$ and $k$ represents as armature slot number, rotor pole number, phase and integer.

$$
N_{r}=N_{s}\left[1 \pm \frac{k}{2 q}\right]
$$

\section{TOPOLOGY SELECTION OF INNER ROTOR PMFSM}

Four topologies of inner rotor PMFSM as illustrated in Figure 3 were comprising a various stator and rotor design has been analysed at no-load and maximum load conditions. The performances were compared by considering various characteristics such as flux linkage, back-emf, cogging torque, average torque and power. The main objective of this comparison is to examine the appropriate topology that gives less back-emf distortion, less cogging torque, high flux linkage, high average torque and power and easy to manufacture.

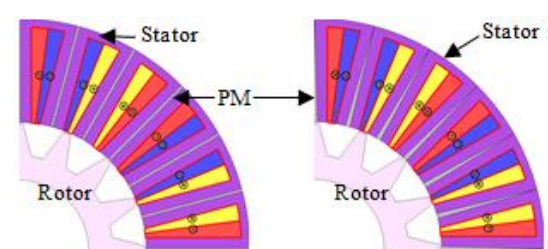

(a) (b)

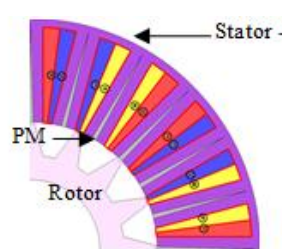

(c)

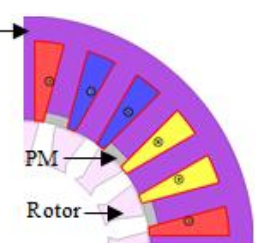

(d)

Figure 3. Cross Section of Various Topologies of Inner Rotor PMFSM, (a) Model 1, (b) Model 2, (c) Model 3, and (d) Model 4 


\subsection{Result of Coil Test and PM Flux Linkage}

At no-load condition, the fluxes from PM excitation as a flux source are linked from the stator to the rotor making a complete flux cycle. By comparing the flux linkages at different coils, the armature coil phases were defined according a balance three phase system. Figure 4 defines three-phase flux linkage as $U$, $\mathrm{V}$, and $\mathrm{W}$ for inner rotor PMFSM (Model 1). The same procedure applies to another model for obtaining three-phase flux linkage connections and validating the operating principle of inner rotor PMFSM. Figure 5 shows the flux linkage at various model of inner PMFSMs at no-load conditions. From the figure, Model 1 with rectangular-shaped PM and segmental stator had highest flux linkage as compared to other inner rotor PMFSM topologies. Obviously, Model 1 configuration had possibility to provide higher torque and power. However the sinusoidal flux has a bit distortion due to flux slightly decreased at 100 degree. In Model 4, the flux linkage waveform was distorted due to a high magnitude of odd harmonics. While, Model 2 and Model 3 which are both topologies used wedge-shaped PM produced low flux linkage but relatively smooth compared to others.

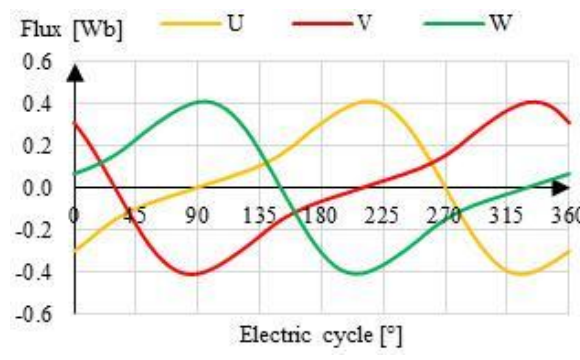

Figure 4. Coil Test for Model

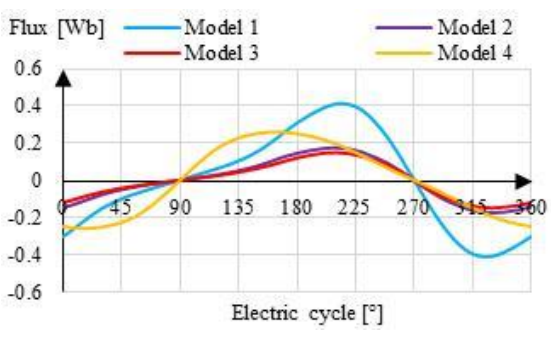

Figure 5. PM flux Linkage at Various Model of Inner Rotor PMFSMs

\subsection{Result of Back-emf}

At open circuit condition, the induced voltage generated from PM excitation with the speed of 750 rpm for topologies of inner rotor PMFSM are illustrated in Figure 6. Model 1 had the highest amplitude of approximately $1217.45 \mathrm{~V}$ while Model 3 motor had the lowest amplitude of $449.49 \mathrm{~V}$ and $12.8 \%$ lower than Model 2. Due to complete flux linkage from stator to rotor and back to stator without any leakage, high backemf was observed. Back-emf waveform of Model 4 was distorted due to odd harmonics 3. Back-emf at no load condition of all topologies was higher than applied voltage of $415 \mathrm{~V}$, but the back-emf can be reduced with several method such as reduce number of turns, optimisation process and decrease of rated current.

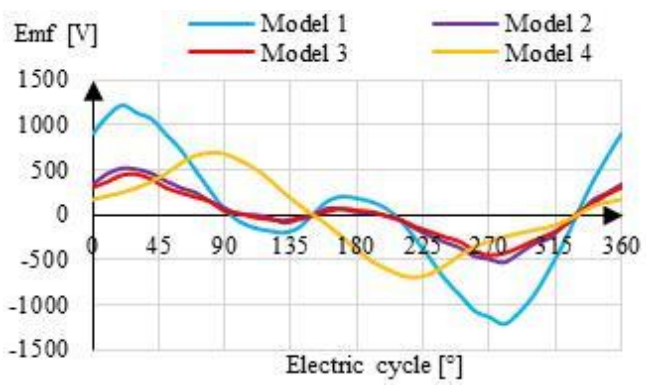

Figure 6. Back-emf Profile at 750 rpm

\subsection{Result of Cogging Torque}

From cogging torque analyses, it is obvious that Model 4 configuration has highest peak-to-peak cogging torque, $T_{\operatorname{cog}}$ followed by Model 1 with $130.8 \mathrm{Nm}$ and $105.6 \mathrm{Nm}$, respectively while Model 2 has the lowest $T_{\operatorname{cog}}$ approximately $51.1 \mathrm{Nm}$. While Model 3 has $52.8 \%$ lower than Model 1 that used rectangular and segmental stator. As high cogging torque caused vibration in machine and made it noisy. The cogging torque also can be reduced by following various cogging torque reduction techniques such as rotor pole chamfering, rotor teeth axial pairing, rotor pole notching, and rotor pole pairing. 


\subsection{Result of Torque and Power}

Following analysis was conducted to determine the maximum ability of the average torque, $T_{\text {ave }}$ and power, $P_{\max }$ at maximum $J_{A}$ with PM excitation. Figure 7 shows the Model 2 has the highest $T_{a v e}$ and $P_{\max }$ of $669.3 \mathrm{Nm}$ of $67.01 \mathrm{~kW}$, respectively due to low $T_{\operatorname{cog}}$ and low distortion in the back-emf. Besides, Model 1 and Model 4 in the lowest position due to suffering from $T_{\operatorname{cog}}$ and high harmonics. Meanwhile, Model 3 has $T_{\text {ave }}$ and $P_{\max }$ of $639.14 \mathrm{Nm}$ and $64.8 \mathrm{~kW}$, respectively. Based on the analysis that has been conducted, Model 3 is selected as the best topology. Although the value of $T_{a v e}$ and $P_{\max }$ slightly lower than the Model 2, the wedge-shaped structure PM and single stator structure causing Model 3 easy to fabricate and simple to optimize. In addition with low harmonics and low back-emf it offers advantages such as ease of protection during the off state occurred due to some faults.

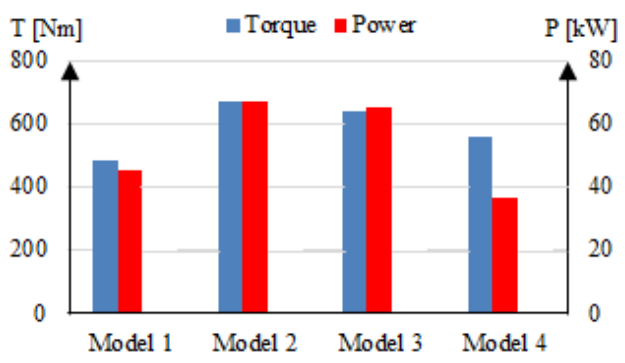

Figure 7. Torque and Power of Various Inner Rotor PMFSMs

\section{VARIOUS ROTOR POLE OF INNER ROTOR PMFSM WITH WEDGE-SHAPED PM}

This study the design of machine focused on the combination of four designs, 24S-8P, 24S-16P, $24 \mathrm{~S}-20 \mathrm{P}$, and 24S-28P due to successfully in coil test analysis. By using the same restriction and specification for all combination of slot-poles of inner rotor PMFSM, the performances are analysed based on 2D-FEA for open circuit conditions, which means there are no current supply in armature coil, while in load condition armature coil supplied at $30 \mathrm{Arms} / \mathrm{mm} 2$ and flux excitation from PM. All designs have similar dimensions such as rotor inner and outer diameter, stator inner and outer diameter, stator tooth width, and area of armature coil, and air gap are illustrated in Figure 8.

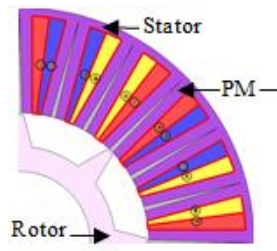

(a)

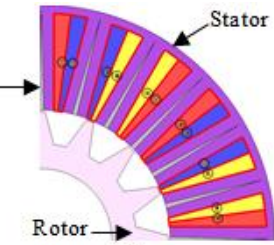

(b)

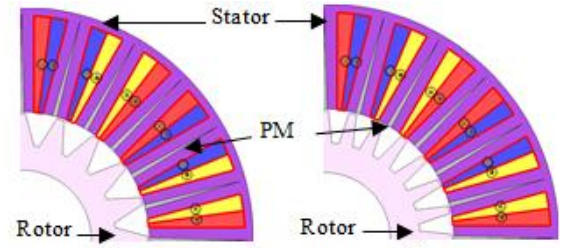

(d)

Figure 8. Various Rotor Pole of Inner Rotor PMFSMs with Wedge-Shaped PM, (a) 24S-8P, (b) 24S-16P, (c) 24S-20P, and (d) 24S-28P

\subsection{Result of Flux Linkage}

The flux linkage of all armature coils are observed and plotted as shown in Figure 9. The results showed that $24 \mathrm{~S}-16 \mathrm{P}$ design has the highest flux linkage, which is $0.149 \mathrm{~Wb}$. However, the flux linkage waveform obtained is not purely sinusoidal due to flux flow from stator to rotor less smooth. For $24 \mathrm{~S}-8 \mathrm{P}$ design, it shows that the magnitude of flux is $0.139 \mathrm{~Wb}$, but the graph shows the magnetic field decreased at 120 degrees till 135 degrees because of the magnetic flux density gradually falling and causing the sinusoidal disruption. The lowest flux linkage has obtained by $24 \mathrm{~S}-28 \mathrm{P}$ design with approximately $6.2 \%$ less compared with 24S-20P design. In addition, both 24S-20P and 24S-28P have purely sinusoidal flux linkage compared to others. 


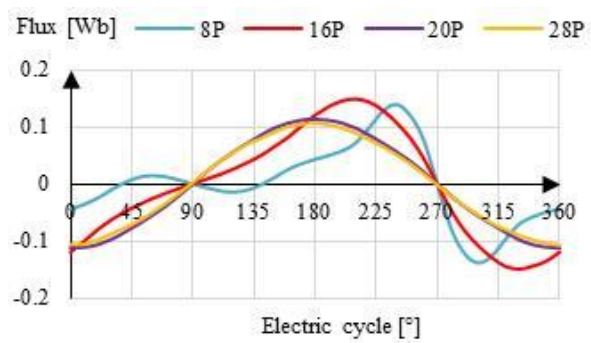

Figure 9. PM Flux Linkage at Various Model of Inner Rotor PMFSMs

\subsection{Result of Back-emf}

The back-emf of various rotor pole of inner rotor PMFSM with wedge-shaped PM at PM excitation are illustrated in Figure 10. From the graph, clearly that the high back-emf of $449.5 \mathrm{~V}$ is generated from 24S$16 \mathrm{P}$ design due to less smooth flux linkage as mention in flux linkage analysis. Meanwhile, the lowest backemf of $309.7 \mathrm{~V}$ is generated from $24 \mathrm{~S}-20 \mathrm{P}$ design. Besides, back-emf of $24 \mathrm{~S}-8 \mathrm{P}$ design was distorted due to high odd harmonic 5, 7 etc. The back-emf of $392.9 \mathrm{~V}$ is generated from 24S-28P design. The back-emf profile is more sinusoidal and smooth than the others due to less harmonic occurred.

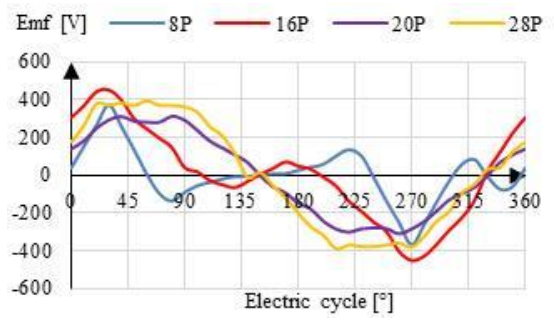

Figure 10. Back-emf Profile of Four Model Inner Rotor PMFSMs

\subsection{Result of Cogging Torque}

Figure 11 shows the result of cogging torque graph for various rotor pole inner rotor PMFSM with wedge-shaped PM. Combination 24S-16 configuration has the highest peak-to-peak cogging torque followed by $24 \mathrm{~S}-8 \mathrm{P}$ with $61.69 \mathrm{Nm}$ and $39.32 \mathrm{Nm}$, respectively. Meanwhile, 24S-28P has the lowest peak-to-peak cogging torque of $4.89 \mathrm{Nm}$. In addition, the peak-to-peak cogging torque of 24S-20P shown $54.7 \%$ higher than 24S-28P. Therefore, by further design refinement and optimisation, it is expected that the peak-to-peak cogging torque of the proposed motor can be reduced to an acceptable condition by using several techniques such as rotor pole skewing, rotor pole notching and rotor pole pairing.

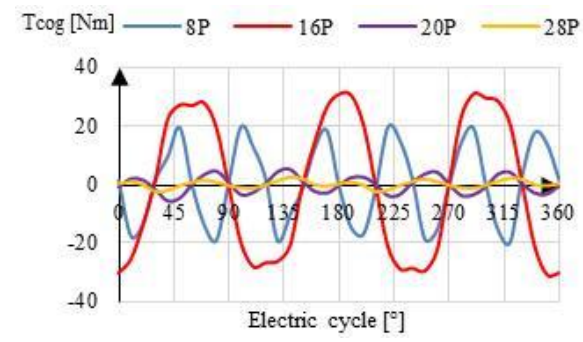

Figure 11. Result of Cogging Torque for Various Model Inner Rotor PMFSMs

\subsection{Result of Torque and Power}

In conjunction, analysis to determine the highest average torque, $T_{\text {ave }}$ and maximum power, $P_{\max }$ at maximum $J_{A}$ is also conducted. The highest $T_{\text {ave }}$ and maximum power are illustrated in Figure 12. It shows, $24 \mathrm{~S}-28 \mathrm{P}$ has the highest $T_{\text {ave }}$ of $905.9 \mathrm{Nm}$, followed by $24 \mathrm{~S}-20 \mathrm{P}$ with $T_{\text {ave }}$ of $903.5 \mathrm{Nm}$. Besides, the lowest 
$T_{\text {ave }}$ of $148.6 \mathrm{Nm}$ is produced from $24 \mathrm{~S}-8 \mathrm{P}$ slot pole combination. Meanwhile, $24 \mathrm{~S}-16 \mathrm{P}$ design has $T_{\text {ave }}$ approximately 4 time higher than $24 \mathrm{~S}-8 \mathrm{P}$. Although the $T_{\text {ave }}$ of $24 \mathrm{~S}-16 \mathrm{P}$ is not the highest, it has the highest $P_{\max }$ of $64.8 \mathrm{~kW}$ due to influenced by the weight of the rotor is lighter than the 24S-28P and 24S-20P designs. In addition, the $P_{\max }$ obtained from $24 \mathrm{~S}-28 \mathrm{P}$ and $24 \mathrm{~S}-20 \mathrm{P}$ are $57.75 \mathrm{~kW}$ and $56.89 \mathrm{~kW}$, respectively. Meanwhile, the lowest $P_{\max }$ of $15.12 \mathrm{~kW}$ is produced from $24 \mathrm{~S}-8 \mathrm{P}$ design.

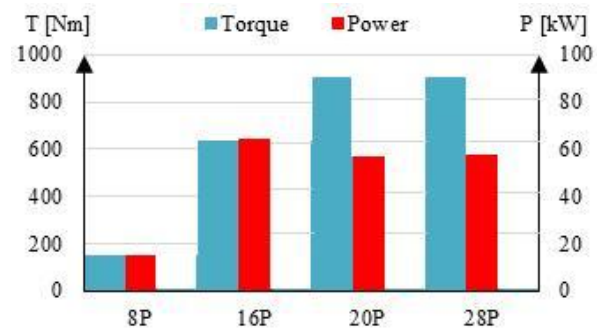

Figure 12. Torque and Power of Various Rotor Pole

Based on the analysis that has been conducted, combination rotor pole of $24 \mathrm{~S}-28 \mathrm{P}$ is selected as the best topology. Although the $P_{\max }$ is slightly lower than $24 \mathrm{~S}-16 \mathrm{P}$, it has the highest $T_{\text {ave }}$ and high flux linkage. In addition, 24S-28P has lowest cogging torque, less harmonic distortion, and lowest torque ripple, which is it made the design less vibration and less noise.

\section{CONCLUSION}

As a conclusion, various designs of inner rotor PMFSMs with wedge-shaped PM for EBs have been investigated. The procedure to design of various inner rotor PMFSMs have been clearly explained. The performances of the PMFSMs at no-load condition such as flux linkage, induced voltage, cogging torque, and at maximum load such as average torque and power shown that $24 \mathrm{~S}-28 \mathrm{P}$ with wedge-shaped PM is the best design. The proposed motor using wedge-shaped PM and single stator structure which is relatively easy to manufacture and easy in optimization process. The initial design has achieved less cogging torque, maximum flux linkage, average torque capability and maximum power of $4.89 \mathrm{Nm}, 3.46 \mathrm{~Wb}, 905.9 \mathrm{Nm}$ and $57.75 \mathrm{~kW}$, respectively. Therefore, the optimisation process needs to be performed in order to increase power of $24 \mathrm{~S}$ 28P with wedge-shaped PM into a suitable power required for the EBs. In addition, iron loss and coper loss analysis should be conducted to find the efficiency of the proposed machine.

\section{ACKNOWLEDGEMENTS}

This work is funded by Research Innovation, Commercialization and Consultancy management (ORICC), Universiti Tun Hussein Onn Malaysia (UTHM) and Ministry of Education Malaysia (MOE) with Vot. No. 1651.

\section{REFERENCES}

[1] R. Reisinger and A. Emadi, "Sensible Transportation Electrification: Get rid of inefficient powertrain designs," IEEE Electrif. Mag., vol. 1, no. 2, pp. 6-12, 2013.

[2] S. Lim and K. T. Lee, "Implementation of biofuels in Malaysian transportation sector towards sustainable development: A case study of international cooperation between Malaysia and Japan," Renew. Sustain. Energy Rev., vol. 16, no. 4, pp. 1790-1800, 2012.

[3] S. Huang and D. Infield, "The potential of domestic electric vehicles to contribute to Power System Operation through vehicle to grid technology," Univ. Power Eng. Conf., pp. 1-5, 2009.

[4] Farzin Piltan, Mozhdeh Piran, Mehdi Akbari and Mansour Barzegar, "Baseline Tuning Methodology Supervisory Sliding Mode Methodology: Applied to IC Engine," International Journal of Advances in Applied Sciences (IJAAS), vol. 1, no. 3, pp. 116-124, 2012.

[5] "European Commission: Europe 2020 Flagship Initiative Innovation Union," Brussels, 2010.

[6] J. A. Xavier, N. A. Siddiquee, and M. Z. Mohamed, "The Government Transformation Programme of Malaysia: a successful approach to public service reform," Public Money Manag., vol. 36, no. 2, pp. 81-87, 2016.

[7] T. S. Ustun, A. Zayegh, and C. Ozansoy, "Electric vehicle potential in Australia: Its impact on smartgrids," IEEE Ind. Electron. Mag., vol. 7, no. 4, pp. 15-25, 2013. 
[8] K. T. Chau and W. Li, "Overview of electric machines for electric and hybrid vehicles," Int. J. Veh. Des., vol. 64, no. 1 , pp. 46-71, 2014

[9] A. Labak and N. C. Kar, "Outer rotor switched reluctance motor design for in-wheel drive of electric bus applications," in 2012 IEEE Int. Conf. Electr. Mach. (ICEM), pp. 418-423, 2012.

[10] Huijuan Liu, Jingxiong Zhang, "PM Design of IPMSM using Parameterized Finite Element Model," TELKOMNIKA (Telecommunication Computing Electronics and Control), vol. 11, no. 12, pp. 7072-7080, 2013.

[11] [11] P. Lindh et al., "Multidisciplinary Design of a Permanent-Magnet Traction Motor for a Hybrid Bus Taking the Load Cycle into Account," IEEE Trans. Ind. Electron., vol. 63, no. 6, pp. 3397-3408, 2016.

[12] [12] A. Y. Anekunu, S. P. Chowdhury, and S. Chowdhury, "A review of research and development on switched reluctance motor for electric vehicles," in 2013 IEEE Power \& Energy Society General Meeting, pp. 1-5, 2013.

[13] [13] Kasrul Abdul Karim, Nurfaezah Abdullah, Auzani Jidin, Tole Sutikno, "Switched Reluctance Motor Initial Design for Electric Vehicle using RMxprt," International Journal of Power Electronics and Drive Systems (IJPEDS), vol. 8, no. 3, pp. 1080-1086, 2017.

[14] [14] Alexander Petrushin, Maxim Tchavychalov, Ekaterina Miroshnichenko, "The Switched Reluctance Electric Machine with Constructive Asymetry," International Journal of Power Electronics and Drive Systems (IJPEDS), vol. 6, no. 1, pp. 86-91, 2015.

[15] [15] N. Zabihi and R. Gouws, "A Review on Switched Reluctance Machines for Electric Vehicles," in IEEE 25th International Symposium on Industrial Electronics (ISIE), pp. 799-804, 2016.

[16] [16] A. S. Thomas, Z. Q. Zhu, R. L. Owen, G. W. Jewell, and D. Howe, "Multiphase Flux-Switching PermanentMagnet Brushless Machine for Aerospace Application," IEEE Trans. Ind. Appl., vol. 45, no. 6, pp. 1971-1981, 2009.

[17] [17] X. Zhu, Z. Shu, L. Quan, Z. Xiang, and X. Pan, "Multi-Objective Optimization of an Outer-Rotor V-Shaped Permanent Magnet Flux Switching Motor Based on Multi-Level Design Method," IEEE Trans. Magn., vol. 52, no. 10 , pp. $1-8,2016$.

[18] [18] W. Fei, P. C. K. Luk, J. Shen, and Y. Wang, "A novel outer-rotor permanent-magnet flux-switching machine for urban electric vehicle propulsion,"

[19] in International Conference on Power Electronics Systems and Applications (PESA), pp. 1-6, 2009.

[20] [19] W. Fei, P. C. K. Luk, J. X. Shen, Y. Wang, and M. Jin, "A novel permanent-magnet flux switching machine with an outer-rotor configuration for in-wheel light traction applications," IEEE Trans. Ind. Appl., vol. 48, no. 5, pp. 1496-1506, 2012.

[21] [20] W. Hua, H. Zhang, M. Cheng, J. Meng, and C. Hou, "An Outer-Rotor Flux-Switching Permanent-MagnetMachine With Wedge-Shaped Magnets for In-Wheel Light Traction," IEEE Trans. Ind. Electron., vol. 64, no. 1, pp. 69-80, 2017.

[22] [21] Lingyun Shao, W. Hua, Z. Q. Zhu, X. Zhu, M. Cheng, and Z. Wu, "A Novel Flux-Switching Permanent Magnet Machine With Overlapping Windings," IEEE Trans. Energy Convers., vol. 32, no. 1, pp. 172-183, 2017. 


\section{BIOGRAPHIES OF AUTHORS}
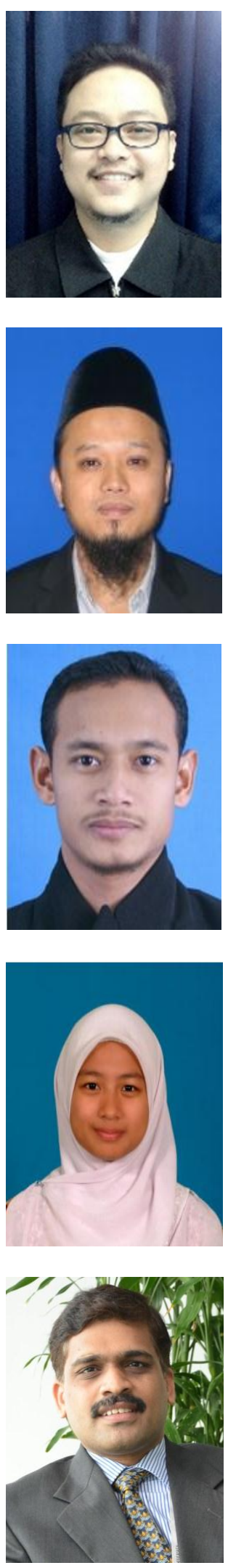

Mohd. Fairoz Omar was born in Johor, Malaysia, on May, 12, 1986. He received Diploma in Electric and Electronic Engineering from Politeknik Ibrahim Sultan in 2008. Since October 2008, he has been working under Asian Geos (M) Sdn. Bhd as Technician. He received his B.E Degree in Electronic Engineering and M.E Degree in Electrical Engineering from University Tun Hussein Onn Malaysia, in 2014 and 2016, respectively. Currently, he is Ph.D. Degree at Department of Electrical Power Engineering, University Tun Hussein Onn Malaysia. His research interests include permanent magnet flux switching machines (PMFSMs) for electric buses

Erwan Sulaiman was born in Johor, Malaysia, on August 31, 1978. He received his B.E and M.E Degrees in Electrical Engineering from University of Malaya in 2001 and University Tun Hussein Onn Malaysia (UTHM) in 2004. He has been with UTHM from December 2004 as a lecturer. He received Doctor Degree in Electrical Engineering from Nagoya Institute of Technology (NIT), Japan in 2012. He is currently senior lecturer at Department of Electrical Power Engineering, University Tun Hussein Onn Malaysia. His research interests include design optimizations of HEFSM, FEFSM, PMFSM, in particular, for HEV drive applications.

Md. Zarafi Ahmad was born in Johor, Malasyia on July 11, 1979. He received his B.E and M.E Degrees in Electrical Engineering from Universiti Teknologi Mara (UiTM) in 2003 and University Tun Hussein Onn Malaysia (UTHM) in 2006. He has been with UTHM from September 2007 as a lecturer. He received Doctor Degree in Electrical Engineering from UTHM in 2016. He is currently senior lecturer at Department of Electrical Power Engineering, UTHM. His research interests include design optimizations of outer rotor hybrid excitation flux switching machine (HEFSM) for HEV applications.

Jaudah Abd Rani was born in Johor, Malaysia on May 11, 1992. She received Bachelor of Electrical Engineering with Honours from Universiti Tun Hussein Onn Malaysia in 2016. In 2015, she joined Assoc. Prof. Dr. Erwan Sulaiman research team as research field assistant to study on stress analysis of E-Core hybrid excitation flux switching motor. Upon graduating her bachelor degree program, she pursue a master degree of Electrical Engineering under Assoc. Prof. Dr. Erwan Sulaiman. Her current research interests include electric machines and drive focusing on single-phase hybrid excitation flux switching motor (HEFSM) with an E-Core stator. She is a member of Board of Engineers Malaysia. She awarded Best Presenter in a conference proceeding of 4th IET International Conference on Clean Energy.

Dr. Chockalingam Aravind Vaithilingam (M'96 SM'17) born in Chennai, India, in 1975. He received the B.E. degree from Bharathidasan university in 1998, M.E from Bharthiyar University in 2001 and the Doctor Degree in Electrical Power Engineering from University Putra Malaysia in 2013. From 2003 till date he worked as key researcher in the design of energy efficient and special electrical machines. Since 2011, he has been a senior lecturer with the School of Engineering, Taylor's University, Selangor, Malaysia. He is the author of five books, more than 150 indexed articles. His research interests include novel energy efficient machines for transportation and alternative energy applications. 